\title{
Nutrition videotapes reach low-income WIC audiences
}

\author{
Amy Block Joy $\square \quad$ Mary Lavender Fujii
}

\begin{abstract}
Although some research exists on the effectiveness of using videotapes to deliver nutrition education to middle-income clients in clinical settings, little has been reported on the effectiveness of this approach in public health environments. This preliminary study evaluated the success of "For Goodness Sake!", a video series teaching nutrition education to low-income participants in the Women, Infants and Children's (WIC) program. Participants reported significant increases in their consumption of broccoli and rice 3 to 4 weeks after viewing the videos.
\end{abstract}

With continuing cutbacks in federal, state and local funding of nutrition programs, nutritionists are seeking more cost-effective education methods. One approach that has proven beneficial in past research is the use of videotaped instruction. Video materials are relatively inexpensive and readily available, and information can be presented in a visually stimulating and convenient manner. Videotaped material also allows the nutrition educator to reach a larger audience with consistent information.

Although research has shown that videotaped and televised instruction is an effective approach to changing nutrition knowledge, attitudes, and behavior, most of the work in this area has been done with middle- to highincome clients in a medical or therapeutic setting. Few reports have been published on the effectiveness of using videotapes to change the knowledge or behavior of low-income audiences. In addition, little has been reported on the efficacy of using videotapes for nutrition education in a public health environment.
This paper reports on a preliminary study that examined the effectiveness of using the "For Goodness Sake!" video series to change the behavior of low-income audiences, as well as the implications of using videotaped instruction to deliver nutrition education.

\section{Methods}

The primary purpose of the Women, Infants and Children's (WIC) program is to improve the health and well-being of low-income pregnant and breastfeeding women and their children. WIC clients are provided food coupons specific to their pregnancy or breastfeeding needs. Despite cutbacks and reduced funding, the program is highly successful. General Accounting Office studies have shown that prenatal WIC benefits reduce the rate of low birthweight babies by $25 \%$; GAO estimates that every $\$ 1$ spent on WIC prenatal services saves $\$ 3.50$, with most savings coming in the first year after birth.

WIC clinics offer an ideal location for short, focused nutrition education interventions. Videotape education is one means by which WIC programs and others provide nutrition education. This preliminary study was done to develop a methodology for studying the effectiveness of videotape instruction and developing recommendations to improve it.

The four-part video series "For Goodness Sake!" was specifically developed for use at agency sites where low-income families congregate. In our study, each videotape ran 3 to 6 minutes and featured one of four foods. Previous research of the spending practices and eating habits of lowincome families had revealed that their diets were low in fruits, vegetables and dairy products, so foods covered in the series included broccoli, nonfat dry milk, low-cost protein

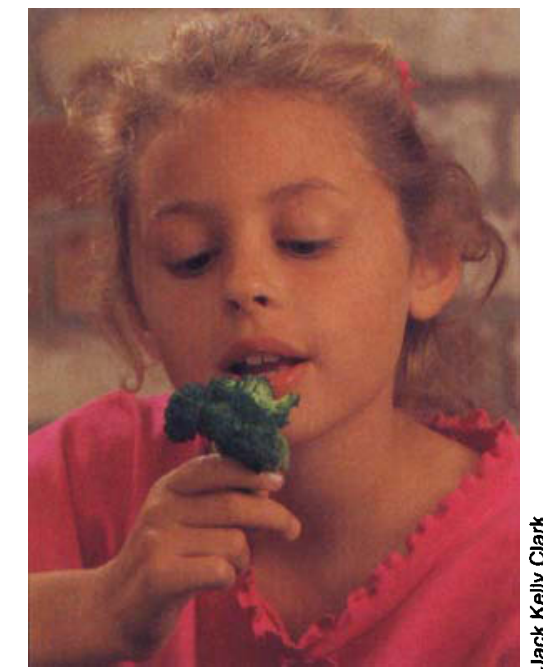

Videotapes shown to low-income families advocated consumption of broccoli, as well as nonfat dry milk, low-cost protein sources and rice.

sources and rice. The videotape featured ways to increase vegetable and milk consumption and ways to stretch the food dollar (using rice and nonfat dry milk). Videotape messages were based on the curriculum of the Adult Expanded Food and Nutrition Education Program. They included: (1) the nutritional value of the food; (2) economical purchase practices; (3) correct preparation and storage practices; and (4) easy, quick and nutritious ways to prepare and use the foods demonstrated.

The videotapes were shown at the Richmond WIC clinic in May through August of 1988. The Richmond WIC clinic is located in a predominantly low-income and ethnically diverse urban area. Clients are scheduled for nutrition education on a regular basis. The "For Goodness Sake!" videos were shown on regular nutrition education days. A classroom was used for nutrition instruction.

During this time, an average of 175 clients were seen daily. The videotape programs were shown four to five times each test day to groups of 15 to 20 WIC clients and their children. Each lesson was approximately 25 minutes long and included an introduction to the video, two pretests, and two posttests following the showing of two videos. Participants also received handouts outlining preparation, proper storage, and recipes. Broccoli and milk videos were shown in May and July and protein and rice videos were shown in June and August. The 
order and pairing of the videotapes were kept consistent and were not seen to be confounding variables.

Pre- and posttests were designed to test for key nutritional concepts, and were pilot-tested for validity. To avoid pretest sensitization, and check for longer knowledge retention, a telephone follow-up interview was conducted 3 to 4 weeks after the viewing using a random sub-sample of study participants.

The pre-/post-questions were intended to evaluate how well participants retained factual information presented in each of the videos. Each test contained four to five multiple choice questions and took an average of 3 to 4 minutes to complete. In order to assess behavioral change, participants were asked both in the pre- and posttests how frequently they consumed the featured food. Telephone interviews included similar questions. These follow-up interviews took from 5 to 10 minutes to complete, depending on the length of the client's answer to open-ended questions.

All tests were scored and entered into a dBASE II program. Statistical Package for the Social Sciences (SPSS/ $\mathrm{PC}+, 1988)$ was used to do two-tailed, paired, sample $t$-tests. The ' $t$ ' value of the differences between pre- and posttest scores, as well as the ' $t$ ' values of differences between pretest scores and telephone interview scores, were computed for each of the four videotapes. The ' $t$ ' values for consumption data were also computed comparing consumption by participants at pretest and telephone interview time points.

A control group was not used in this study for two reasons. This was primarily a preliminary study to assess the methodological constraints of working in a clinical setting. Researchers wanted to determine if videotape instruction was practical and could affect the knowledge and behavior of participants. In addition, an experimentally controlled study is very costly to do. The lack of a control group, however, indicates that results should be viewed as preliminary.

\section{Results}

A total of 225 WIC clients saw the "For Goodness Sake!" videos and were

\begin{tabular}{|c|c|c|c|c|}
\hline Videotape viewed & n & $\begin{array}{l}\text { Total pre/post } \\
\text { possible } \\
\text { score }\end{array}$ & $\begin{array}{l}\text { (Pre/post) } \\
\text { mean } \\
\text { difference }\end{array}$ & t-value* \\
\hline \multicolumn{5}{|l|}{ Broccoli } \\
\hline total sample & 110 & 8 & 1.90 & 10.85 \\
\hline \multirow{2}{*}{\multicolumn{5}{|c|}{ Milk }} \\
\hline & & & & \\
\hline total sample & 110 & 6 & 1.76 & 11.59 \\
\hline sub-sample & (36) & 6 & 2.47 & 6.96 \\
\hline \multicolumn{5}{|l|}{ Protein } \\
\hline total sample & 115 & 14 & 4.34 & 16.85 \\
\hline sub-sample & (39) & 14 & 5.00 & 12.37 \\
\hline \multicolumn{5}{|l|}{ Rice } \\
\hline total sample & 115 & 7 & 1.98 & 11.89 \\
\hline sub-sample & (39) & 7 & 1.97 & 7.81 \\
\hline \multicolumn{5}{|c|}{$\begin{array}{l}\mathrm{P}<.001 \\
t \text { sub-sample is composed of a random number of study participants interviewed } 3 \text { to } 4 \text { weeks after posttest } \\
\text { by telephone. }\end{array}$} \\
\hline \multicolumn{5}{|c|}{$\begin{array}{l}\text { TABLE 2. The average consumption (times per month) of broccoli, milk and rice reported by a } \\
\text { sample of WIC clients (pretest and telephone follow-up measures) }\end{array}$} \\
\hline $\mathrm{n}^{*}$ & Pretest & $\mathbf{n}^{*}$ & $\begin{array}{l}\text { Telephone } \\
\text { follow-upt }\end{array}$ & Change \\
\hline \multicolumn{5}{|c|}{ 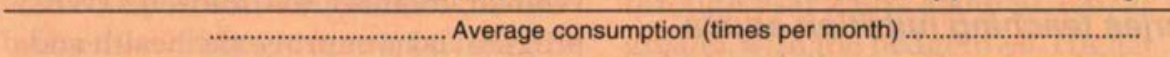 } \\
\hline Broccoli & 4.0 & 28 & 7.0 & $+3.0 \neq$ \\
\hline Milk & 1.6 & 24 & 3.4 & +1.8 \\
\hline Rice & 8.0 & 34 & 12.0 & $+4.0 \neq$ \\
\hline \multicolumn{5}{|c|}{$\begin{array}{l}\text { "number of respondents who supplied data. } \\
\text { tpretest question asked how often they eat the food illustrated (i.e., broccoli, milk, rice). Telephone inter- } \\
\text { view question asked the respondent how often they now eat the food illustrated on the videotape. The num- } \\
\text { ber represents the average number of times per month the food was consumed for three of the videotapes. } \\
\ddagger P<.05\end{array}$} \\
\hline
\end{tabular}

given pre- and posttests. Of these, 75 randomly selected clients completed the follow-up telephone interview. Of the 225 participants interviewed, $63 \%$ were black, $20 \%$ white, $9 \%$ Hispanic and $8 \%$ Asian. The majority of participants were female $(96 \%)$. The subsample telephone follow-up population had a similar ethnic profile. Significant $(P<.001)$ improvements in nutrition knowledge were seen in posttests given immediately after viewing and 3 to 4 weeks later (table 1). Statistically significant increases $(P<.05)$ were reported in the consumption of broccoli and rice 3 to 4 weeks after viewing the "For Goodness Sake!" videos (table 2).

Participants did not appear to significantly increase their consumption of nonfat dry milk after viewing the video. We noted that consumption of nonfat dry milk was difficult to increase because most people found it unpalatable. The videotape suggested using nonfat dry milk in recipes so that its taste is insignificant. The results may have been better if one of the recipes had been demonstrated in conjunction with the videotape.
The study did not attempt to assess consumption practices of low-cost protein since this video featured a large number of protein sources.

\section{Discussion}

This study demonstrates the effectiveness of using the "For Goodness Sake!" videotapes to teach nutrition education to low-income WIC audiences. Participants learned simple, nutritious ways to prepare the foods, the nutritional value of each food featured, and economical purchasing practices. Watching the "For Goodness Sake!" videos also appeared to increase the consumption of broccoli and rice. These findings agree with research results for other audiences.

The study demonstrates that videotaped instruction can be useful in increasing nutrition knowledge and food-related behavior of low-income participants. Such videotaped instruction is inexpensive, visually stimulating and allows the nutrition educator to reach large audiences with consistent information. More nutrition videotapes offering short and focused information are needed, especially for 
use in public health clinics and other waiting rooms (e.g., Food Stamp offices, county welfare departments, etc.). With budget cuts and reduced staffing, the time spent on nutrition education is minimal. Videotape education offers an alternative to a "chaotic" waiting room situation. Participants in this study reported that their children, often accompanying them in waiting rooms, were attentive to the videotapes. In addition, since the videotapes are short, the amount of time spent watching them is brief. Focusing on specific content is more effective because people may be overwhelmed by too much information. The "For Goodness Sake!" series now includes several more topics: chicken, one-pot meals, snacks and vegetables.

One of the difficulties in assessing the significance of these results is the lack of a control group. Further research to evaluate the effectiveness of videotaped instruction with a control comparison group is currently being done. Funding of $\$ 73,000$ has been approved by the USDA to test this method and compare it with a control group in three California counties Contra Costa, Sonoma and Stanislaus. Results of the experimentally controlled research study will be available in October 1995.

A. Block Joy is Academic Specialist, Department of Nutrition, UC Davis; $M$. Lavender-Fujii is Home Economist, Contra Costa County Cooperative Extension.

Funding was provided, in part, by the US Department of Agriculture, Cooperative Extension Service.

The authors acknowledge the following individuals: Anne Wright (statistical analysis), Diane Ungson (instruction of participants, data collection and summary report), Isabel Balazs (instruction of participants and data collection) and Jim Mulroney (report assistance). In addition, the authors express their appreciation to Dorothy Conway, Director of WIC, and her staff as well as the WIC clients who participated in the study.

For further information, readers may wish to consult published research regarding the effectiveness of videotaped instruction. A list of references can be obtained from the author.

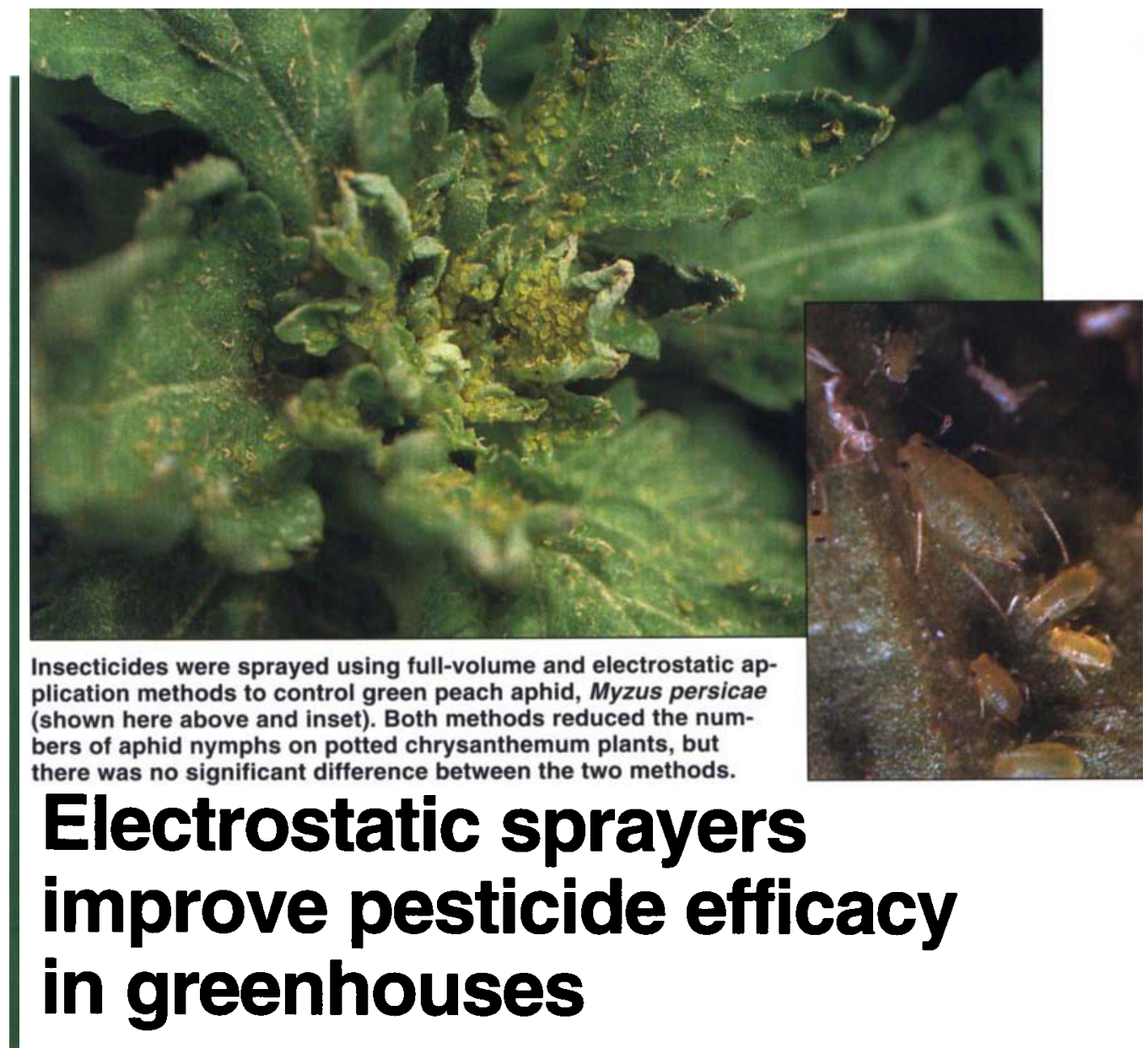

John Kabashima

D D. Ken Giles

口 Michael P. Parrella

Electrostatic sprayers represent a new development in greenhouse pesticide application technology. In a 3-year study, we evaluated one of the newer candidate sprayers for efficacy in controlling green peach and melon aphids while enhancing worker safety. Electrostatic application provided aphid control that was equal or superior to conventional fullvolume spray while using $\mathbf{4 0}$ times less water in an equivalent area. In addition, although electrostatic application provided 3.7 times more foliar deposition than the use of conventional fullvolume sprays, electrostatically deposited residues were more difficult to remove mechanically. Therefore, residues from electrostatic application are less hazardous to worker health and safety than conventional full-volume wet sprays.
The application of pesticides in greenhouses devoted to the production of ornamental plants is dominated by the use of fully dilute wet sprays under the historical concept of "spray to runoff." It is common for applications to be in the range of 100 to 800 gallons per acre, depending on the type of crop, its stage of growth and the target pest. It has been documented that this is a grossly inefficient use of pesticides, with less than $1 \%$ of the active ingredient applied actually reaching the target pest. Despite this lack of efficiency, the ease, convenience and familiarity of this application method have made it routine among growers. In addition, pesticide labels consistently reinforce this application technology and have contributed to continued dominance of dilute sprays in the greenhouse.

This type of pesticide application is clearly inconsistent with the principles and practices of integrated pest management (IPM), which strive for con- 